\title{
High latitude local scale temperature complexity: the example of Kevo Valley, Finnish Lapland
}

\author{
G. Pike,* N. C. Pepin and M. Schaefer \\ Department of Geography, Buckingham Building, Lion Terrace, University of Portsmouth, UK
}

\begin{abstract}
Subarctic Scandinavia is expected to experience significant temperature increases over the next century. How this increase will influence local scale climate is largely unknown. This study examines local scale temperature variability in the subarctic where the unusual solar geometry means that the classic diurnal cycle of mid-latitudes has limited application.

Near surface air temperature data were collected from a high density network of 60 temperature data loggers covering approximately $20 \mathrm{~km}^{2}$ in the valley system around Kevo Subarctic Research Station $\left(69^{\circ} 45^{\prime} \mathrm{N}, 27^{\circ} 1^{\prime} \mathrm{E}\right)$. Temperature data was collected at 30 min intervals from September 2007 to March 2010, along with additional temperature and cloud cover data from the Kevo station. NCEP/NCAR reanalysis data was used to reconstruct synoptic conditions for the area at 6-h intervals. Lapse rates and regression of surface temperatures on free air temperatures are used to investigate local temperature variability. Median absolute yearly deviation analysis of the site temperatures was used to assess the representativeness of Kevo Station.

The results show intense (up to $+80^{\circ} \mathrm{C} \mathrm{km}^{-1}$ ) and persistent inversion events during the winter months (NDJ) which are broken up by mechanical effects. In the transition from winter into spring (FMA) these inversions still occur but increasing radiation imposes a diurnal pattern on their formation and destruction. As snow cover peaks in spring the interaction between surface albedo, land cover and radiation serves to amplify the diurnal cycle in lapse rates. Summer lapse rates are modified by the presence of open water at low elevations. These results suggest that expected land cover and synoptic changes due to regional warming will act to decrease the frequency and intensity of inversion formation, steepening mean lapse rates and therefore increasing the relative amount of warming in valley floor locations. Copyright (C) 2012 Royal Meteorological Society
\end{abstract}

KEY WORDS lapse rates; microclimate; complex topography; decoupling; high latitude; subarctic; Finland

Received 25 October 2011; Revised 2 July 2012; Accepted 14 July 2012

\section{Introduction}

It is increasingly important to understand the complexity of surface climate at the local-scale for many reasons. There is the need to downscale predictions of climate change (Trivedi et al., 2008; Zhenlin et al., 2011) and interpret palaeoclimatic reconstructions from point sources (Brooks, 2006). Many environmental processes respond to local-scale climate drivers as much as broad regional climate. For example, refugia are in part defined by micro-climate, and are extremely important in terms of climate change impacts on species' distributions and change (Ashcroft, 2010; Dobrowski, 2011).

Thus studies across a diverse range of interests have always highlighted the need for a more detailed understanding of local climates. Such interests have included improving palaeoclimate reconstructions (Brooks, 2006), modelling climate in areas of complex topography for prediction of frost (Blennow and Persson, 1998), road icing (Gustavsson et al., 1998), the management of

* Correspondence to: G. Pike, Department of Geography, Buckingham Building, Lion Terrace, University of Portsmouth, PO1 3HE, UK.

E-mail: gary.pike@port.ac.uk agricultural activities (Orlandini et al., 2006), and understanding local ecology (Armbruster et al., 2007).

There is also an increasing awareness of the importance of microclimate in determining environmental response to climate change. Dobrowski et al. (2009) show that it is important to understand the topographic controls of microclimate in the present day in order to be able to understand ecological responses in areas of complex topography. Daly et al. (2009) show that local scale climate complexity may cause future climate warming to be amplified or reduced at individual locations in the Oregon Cascades, compared against broad regional changes. The extent to which local contrasts in warming rates due to cold air drainage are evident in past instrumental records in the western US is investigated by Pepin et al. (2011) but there are no simple patterns. Lundquist and Cayan (2007) have shown that topography can even induce opposite trends in climate at contrasting sites in a small region of the Sierra Nevada, because synoptic climatology influences climate in different ways at different locations. Thus is it clear that local scale climate studies are needed to obtain a greater understanding of future climate change. 
Of necessity, large-scale relatively coarse datasets are used to model future climate scenarios. This regional response needs downscaling both in terms of spatial scale, and from free air to surface conditions which are often contrasting. Ensemble and nested modelling approaches have served to improve the downscaling of climate predictions (e.g. Benestad, 2002, 2004) but it is still recognised that there are issues with downscaling regionalscale data and that it is necessary to collect empirical data at the local scale to validate such approaches (Dobrowski, 2011).

Temperature is considered the most important factor in a broad range of ecological processes (e.g. Blandford et al., 2008). It is also the factor about which most is known in terms of the response to climate forcings. Thus many of the studies previously mentioned focus particularly on local-scale temperature variability (e.g. Lundquist and Cayan, 2007; Daly et al., 2009). Many of these studies also focus on regions of complex terrain, where the combined influence of topography, aspect, elevation, exposure and varied surface characteristics makes downscaling particularly challenging (Ashcroft, 2010).

This article concentrates on quantifying local-scale temperature variability in a region of complex terrain at the edge of the Arctic where the unusual solar geometry plays an additional important role. The region is the far northern district of Finland, on the eastern side of the Scandes mountain range (Figure 1). More detailed information on the study area is given in section 3 .
There are many reasons why the sub-Arctic region is particularly important for detailed study. The Arctic is expected to warm more rapidly than other parts of the globe (ACIA, 2004; Serreze and Francis, 2006) due to polar amplification (IPCC, 2007). Environmental changes will be especially pronounced at the edges of the Arctic where northward migration of the forest/tundra ecotone is expected (Gutman and Reissell, 2010), and decreases in permafrost may lead to positive feedbacks on global climate as methane hydrates are released (Isaken et al., 2011). Cryospheric changes are likely to be marked, including a decrease in snow and ice cover (Lemke et al., 2007) and a change in the length of snow season.

The high latitude (the region is above the Arctic Circle) means that the solar geometry has a complex influence on local climate which is highly seasonally dependent. Local scale decoupling of surface climate from the free atmosphere occurs through cold air drainage and this can become persistent in a climate dominated by a negative radiation balance (Pepin et al., 2009). This means that regional scale lapse rates controlled by air-mass and synoptic climatology have little relevance on the ground. Furthermore, during the polar night/day, $24 \mathrm{~h}$ sunlight/complete lack of sunlight, mean that the normal models of cold air drainage (Whiteman, 1982; Neff and King, 1989; Whiteman et al., 1999, 2004; Iijima and Shinoda, 2000; Lundquist et al., 2008) which are based on the diurnal cycle typical of mid-latitudes, are not always applicable. This also applies to models of aspect effects. Many of the classic studies of local scale

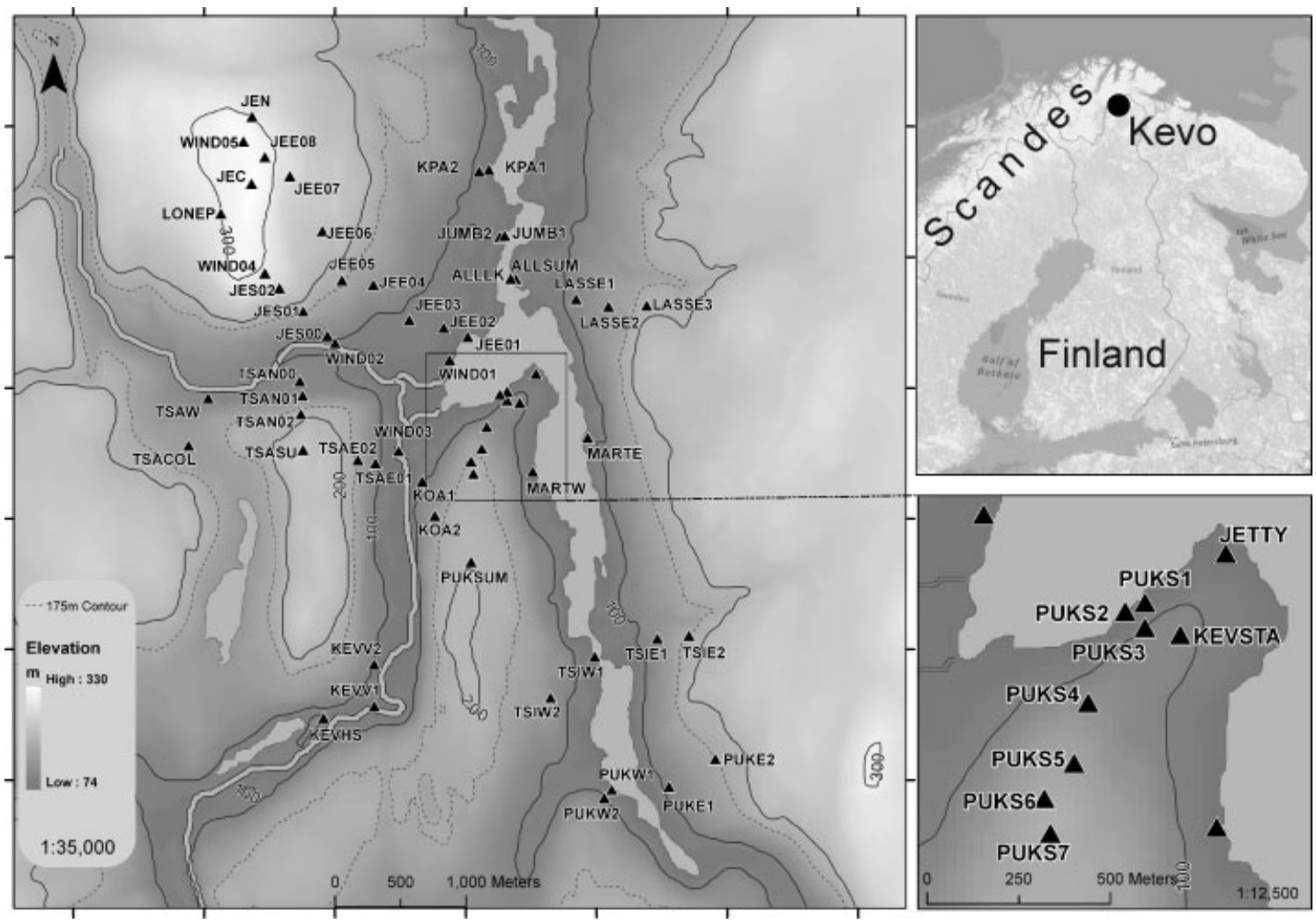

Figure 1. Map of study area in northern Finland, showing the location of the 60 logger sites, and the Kevo Meteorological station. The 46 sites selected are identified in Table I. 
topographical effects on climate therefore need to be modified in the sub-Arctic.

Finally the European sector of the Arctic is of particular interest from a palaeoclimate perspective, because of the inherent instability of the thermohaline circulation (Bond et al., 1997, 2001). There is great interest in understanding rapid climate changes in this region based on palaeoclimate proxies derived from locations across this landscape [e.g. Weckström and Korhola (2001) (diatoms), Luoto (2009) (chironomids)]. More information on localscale climate complexity is therefore essential in helping to interpret such proxies (Brooks, 2006).

In this article, we assess the effect of local scale topography on local climate in northern Finland through developing models of observed spatial temperature variation using a variety of statistical techniques (regression and deviation analysis). We assess the representativeness of an established weather station in terms of the local climate and discuss the possible implications of future climate change on spatial temperature patterns in the study area.

\section{Aims}

The aims of this study are:

1. To obtain detailed high resolution (spatial and temporal) temperature data for a large number of sites (>50) over a three year period (2007-2010) in our local study region. This will give us a detailed microclimate data set for the study site and the time period covered will give some indication of interannual variability.

2. To describe in detail the observed local climate in the Kevo region of northern Finland through developing an appreciation of how cold air drainage and aspect effects modify any elevational effect (lapse rates). The high latitude solar geometry and diverse seasonality give rise to a complex local scale picture.

3 . To examine the representativeness of established longterm station data (1962-2010) at Kevo Subarctic Research Station, in particular the extent to which the local climate complexity is captured at this location. Typically meteorological stations are spaced many tens of kilometres apart, ideally in a location that is as representative of the surrounding terrain as possible. How representative is the station in our study area and what does it represent?

4. To assess the implications of these findings for predicting spatial patterns of long term climate change in this region.

\section{Study area}

The field site is centred on the Kevo Subarctic Research Station $\left(69^{\circ} 45^{\prime} \mathrm{N}, 27^{\circ} 1^{\prime} \mathrm{E}\right)$ in the north of Finland (Figure 1) on the shores of Kevojarvi (a fjord). The regional climate is influenced by proximity to the North
Atlantic to the north and west, which has a moderating maritime effect on temperatures, and the continental landmass to the south and east which allows high pressure systems to drive warm, sunny summers and cold winters. Overall the regional climate is more continental than might be expected because of the sheltering effect of the Scandes mountain range from the prevailing westerly winds, combined with an additional barrier effect which reduces mean annual precipitation to around $500 \mathrm{~mm}$ (Autio and Heikkanen, 2002).

At $3^{\circ}$ above the Arctic Circle the polar night lasts from November 27 until January 15. During this period there is no direct sunlight. Conversely the polar day lasts from May 18 until July 25 when the sun does not set. During the spring and autumn there is a more typical diurnal cycle, but the solar elevation remains low (noon solar elevation at the equinox is only $20^{\circ}$ ) which means that aspect effects become important.

The terrain around the research station consists of incised valleys running through otherwise gently rolling fell terrain. At the bottom of the valley lies Kevojarvi ('lake' in Finnish) which is typical of the valley systems in the area. Whilst the area could not be described as mountainous (there is an altitude difference of $245 \mathrm{~m}$ between the valley floors and the summits), the local topography is steep, with cliffs and incised glacial valleys. Therefore the local climate is undoubtedly complex, aided by low solar elevation and pronounced shading effects. Kevo valley is around $60 \mathrm{~km}$ poleward of the continuous northern pine treeline (Vainio, 2011) and is thus an outlier in ecological terms; Scots pine (Pinus sylvestris) and Mountain birch (Betula pubescens) cover the sheltered valley area, with limited aspen (Populus tremula) on some south-facing slopes. Tree cover reduces quickly with altitude, the pine limit at approximately $200 \mathrm{~m}$ and mountain birch extending higher to around $250 \mathrm{~m}$. Above the treeline lies arctic heathland and open rocky fellsides. There is a distinct contrast in local climate between the windy and exposed higher elevations (limited snow accumulation and moderate temperatures) and the sheltered valley bottoms (deeper snow cover and a much wider range of temperatures). Lakes are frozen for over half of the year and thus lose their moderating influence in winter (Vajda and Venäläinen, 2003).

\section{Data and methods}

\subsection{Data collection}

Sixty temperature dataloggers (Gemini Series, Hobo U23-001 and Pro Series) were installed in September 2007 at a wide range of sites in an area of approximately $20 \mathrm{~km}^{2}$ surrounding Kevo Sub-Arctic Research Station (Figure 1). The small numbers of Gemini and Pro Series loggers initially used were gradually phased out, replaced with Hobo U23-001 loggers. The spatial distribution included elevational transects on each aspect, along with a representative sample of topographic features such as ridges and valley bottoms. Table I lists 
Table I. Site characteristics for the 60 sites, including elevation, slope, aspect and exposure (topographic curvature). Stations in bold (46) were used in the lapse rate models. Site names are also listed on Figure 1.

\begin{tabular}{|c|c|c|c|c|c|c|c|c|c|}
\hline Site & Slope & Aspect & Exp & Elev & Site & Slope & Aspect & Exp & Elev \\
\hline Alllk & 9 & SW & -0.79 & 76 & Marte & 17 & NW & 0.12 & 80 \\
\hline Allsum & 18 & SW & 0.64 & 100 & Martw & 8 & $\mathbf{E}$ & -1.31 & 75 \\
\hline Jec & 2 & $\mathbf{E}$ & 0.95 & 330 & Puke1 & 11 & SW & -0.26 & 107 \\
\hline Jee01 & 4 & $\mathbf{S}$ & -0.55 & 75 & Puke2 & 8 & SW & 0.14 & 174 \\
\hline Jee02 & 6 & SE & 0.17 & 87 & Puks1 & 14 & NW & -0.96 & 74 \\
\hline Jee03 & 2 & $\mathbf{S}$ & 0.07 & 97 & Puks2 & 5 & NW & -0.69 & 83 \\
\hline Jee04 & 7 & SE & 0.15 & 141 & Puks3 & 22 & NW & 0.94 & 92 \\
\hline Jee05 & 13 & SE & 0.47 & 180 & Puks4 & 13 & $\mathrm{~S}$ & 0.17 & 120 \\
\hline Jee06 & 3 & SE & 0.23 & 225 & Puks5 & 8 & $\mathrm{NE}$ & 0.08 & 184 \\
\hline Jee07 & 8 & SE & 0.48 & 273 & Puks6 & 11 & NW & 0.45 & 159 \\
\hline Jee08 & 8 & $\mathbf{E}$ & 0.38 & 314 & Puks7 & 4 & SE & 0.65 & 176 \\
\hline Jen & 18 & $\mathrm{NE}$ & 0.48 & 300 & Puksum & 0 & $\mathbf{N}$ & 0.04 & 200 \\
\hline Jes00 & 13 & $\mathbf{S}$ & 0.03 & 105 & Pukw1 & 7 & NE & -1.19 & 76 \\
\hline Jes01 & 16 & SE & 1.02 & 180 & Pukw2 & 17 & NE & -0.28 & 101 \\
\hline Jes02 & 22 & SE & 0.12 & 249 & Tsacol & 2 & NE & -0.18 & 151 \\
\hline Jetty & 5 & $\mathrm{NE}$ & -0.38 & 77 & Tsae01 & 20 & $\mathrm{E}$ & 1.07 & 116 \\
\hline Jumb1 & 2 & $\mathrm{NE}$ & -0.16 & 80 & Tsae02 & 22 & $\mathbf{E}$ & 0.41 & 168 \\
\hline Jumb2 & 7 & $\mathrm{E}$ & -0.20 & 93 & Tsan00 & 0 & $\mathbf{F}$ & 0 & 110 \\
\hline Kevhs & 15 & SE & -0.50 & 98 & Tsan01 & 24 & $\mathbf{N}$ & -0.58 & 121 \\
\hline KevoSta & 5 & $\mathrm{E}$ & 0 & 101 & Tsan02 & 15 & NE & 0.49 & 190 \\
\hline Kevv1 & 1 & SE & -0.08 & 85 & Tsasu & 5 & SE & 0.92 & 229 \\
\hline Kevv2 & 23 & $\mathbf{E}$ & -0.43 & 105 & Tsaw & 4 & NE & -0.69 & 110 \\
\hline Koa1 & 11 & NW & 0.88 & 102 & Tsie1 & 12 & $\mathbf{W}$ & 0.08 & 131 \\
\hline Koa2 & 19 & W & -0.54 & 146 & Tsie2 & 11 & NW & 0.04 & 176 \\
\hline Kpa1 & 5 & $\mathrm{E}$ & -0.56 & 78 & Tsiw1 & 3 & SE & 0.03 & 78 \\
\hline Кра2 & 9 & $\mathbf{E}$ & 1.29 & 99 & Tsiw2 & 19 & NE & 0.64 & 145 \\
\hline Lasse1 & 7 & $\mathrm{~W}$ & -0.14 & 110 & Wind01 & 1 & SE & -0 & 76 \\
\hline Lasse2 & 10 & SW & -0.33 & 143 & Wind02 & 7 & $\mathbf{S}$ & -0.36 & 94 \\
\hline Lasse3 & 7 & NW & 0.23 & 191 & Wind03 & 0 & $\mathbf{F}$ & 0 & 80 \\
\hline \multirow[t]{2}{*}{ Lonep } & 7 & W & 0.23 & 300 & Wind04 & 10 & SE & 0.34 & 292 \\
\hline & & & & & Wind05 & 0 & NE & 0 & 325 \\
\hline
\end{tabular}

land cover characteristics for the 60 sites, including slope gradient, aspect, exposure, and elevation. Exposure is derived from the DEM (resolution $25 \mathrm{~m}$ ) based on a $3 \times 3$ grid using ArcGIS v10. More positive values indicate peaks (convex) and more negative values depressions (concave). Values around zero indicate a uniform surface, although that surface may be sloping. The elevation ranges from lake level $(75 \mathrm{~m})$ to the summit of Jesnalvarra $(330 \mathrm{~m})$ - the highest point in the local vicinity, although much higher land lies to the north and west just outside the study area. We aimed to cover all facets of the landscape evenly. There are approximately equal numbers of sites classified as having northerly/southerly components to the aspect (column 2 of Table I) and a chi-square analysis of site compared to DEM derived aspect/elevation/exposure suggested no significant bias in sampling.

Loggers were shielded by Stevenson screens (Figure 2) installed at a height of $1.5 \mathrm{~m}$ above ground level on the north side of trees or other solid structures (i.e. fence posts above treeline). The screen height was not adjusted for snow cover, so in the winter, the effective height above ground level was reduced. However, in the 3 years of operation no screen was buried by snow. The mean maximum snow depth at this location is around $60-70 \mathrm{~cm}$ in March (Vainio, 2011). Measurements began at the beginning of September 2007 and have continued to date, although this article uses data up to March 2010 (a period of 30 months including three winters). Measurements of air temperature were obtained every $30 \mathrm{~min}$, but only $6 \mathrm{~h}$ measurements [0200, 0800, 1400 and 2000 Finnish Standard Time (FST $=$ UTC $+2 \mathrm{~h})$ ] are used in this article, allowing a comparison with free atmospheric temperatures.

Loggers were calibrated in the laboratory beforehand and the maximum range in response (difference between loggers) was shown to be $\pm 0.3{ }^{\circ} \mathrm{C}$ at room temperature $\left(\sim 18^{\circ} \mathrm{C}\right)$, with a similar response at $-25^{\circ} \mathrm{C}$. The vast majority of loggers were within $\pm 0.1^{\circ} \mathrm{C}$ of one another. Because these differences are small in comparison with the environmental temperature differences being measured (sometimes up to $20^{\circ} \mathrm{C}$ at any one time), calibration changes have not been applied to the original data. Additionally loggers were swapped over in the field for logistical reasons and so over time the effects of individual loggers were likely to cancel each other out to some extent at any one location. Subsequent errors in lapse rate 


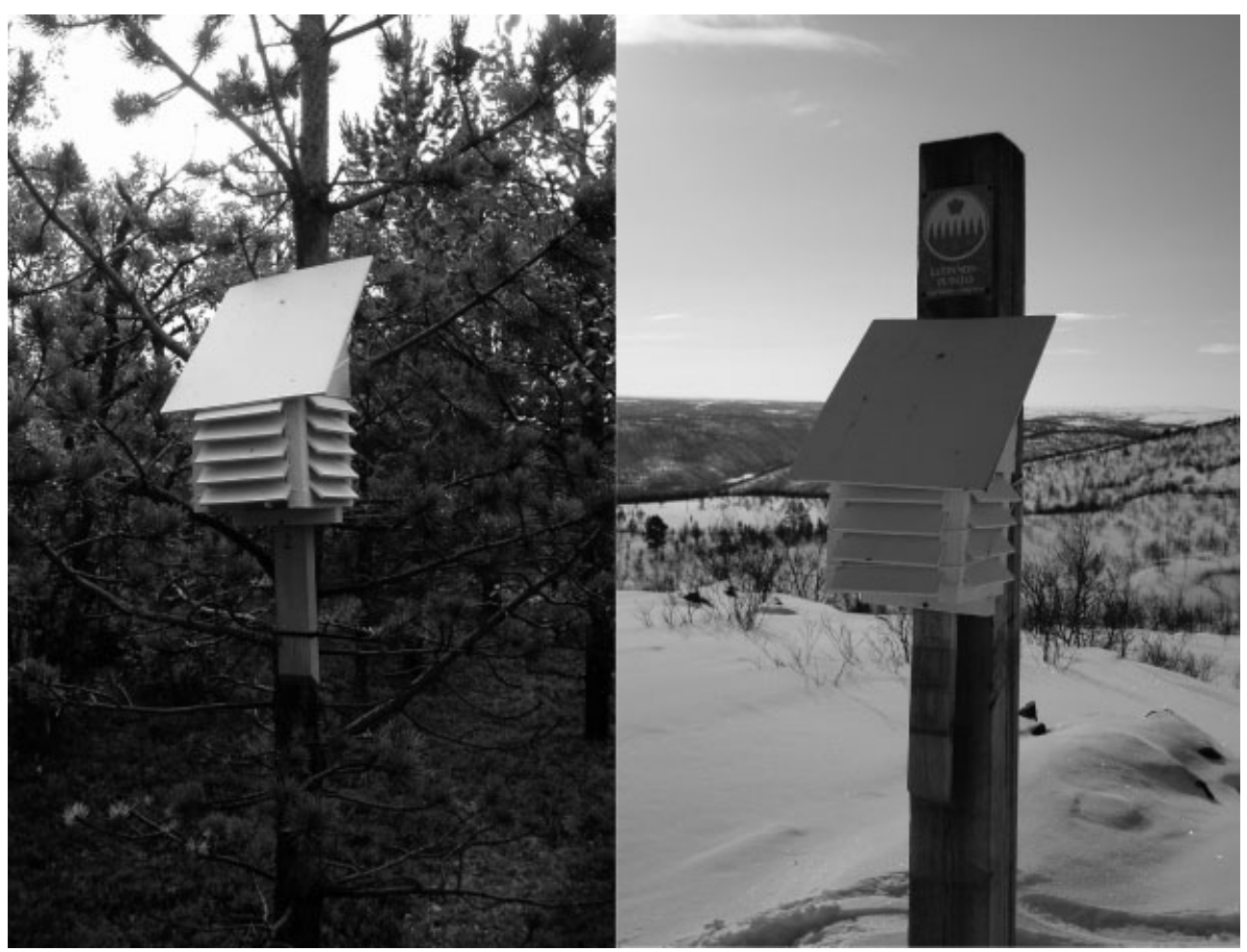

Figure 2. Temperature dataloggers housed in Stevenson screens and installed at $1.5 \mathrm{~m}$ above ground level below the treeline (left) and above the treeline (right).

calculation (based on 46 loggers - see section 4 b) were expected to be minimal.

Secondary data was obtained from Kevo meteorological station (summary monthly and daily records, 1962-2008 (Vainio, 2011)), and from the NCEP/NCAR reanalysis R1 (Kistler et al., 2001). Also $6 \mathrm{~h}$ surface data, including temperature and cloud cover for Kevo Station, were downloaded from http://meteo.infospace.ru/ main.htm. These were used to examine general relationships between long-term climate at Kevo and synoptic controls which strengthens inferences made from the more recent datalogger data. The reanalysis was used to derive a 6-h synoptic classification $(0000,0600,1200$ and 1800 UTC) based on objective flow indices (Daly et al., 2009).

The reanalysis data $\mathrm{R} 1$ is produced jointly by the National Centers for Environmental Prediction (NCEP, formerly 'NMC') and the National Center for Atmospheric Research (NCAR). It is an atmospheric analysis of the state of the global climate system using historical data from 1948 onwards (Kistler et al., 2001). Fields are available on a $2.5^{\circ}$ grid every $6 \mathrm{~h}$ at 17 pressure levels from $1000 \mathrm{mb}$ up to $10 \mathrm{mb}$. We used $850 \mathrm{mb}$ geopotential heights to calculate flow strength and atmospheric vorticity over northern Fennoscandia. This level represents the lower 'free atmosphere' above the local topography which rises to over $1000 \mathrm{~m}$ in the Scandes. Each $6 \mathrm{~h}$ pressure field also resulted in a synoptic classification which attempted to replicate the Lamb classification (Lamb, 1972; Jones et al., 1993). More details of the methods are also given in Losleben et al. (2000). The number of anticyclonic minus cyclonic days was used to derive a monthly anticyclonicity index $(\mathrm{A}-\mathrm{C})$ after Daly et al. (2009) and the days with straight isobars (neither anticyclonic nor cyclonic) were summed to derive a zonal index representing air mass advection.

\subsection{Analytical methods}

A range of analytical methods was used to model the spatial temperature field and its temporal variability. Since elevation is the dominant factor, lapse rate models were derived first. Inversions were identified by positive lapse rates (>zero). Subsequent analyses considered individual stations and their representativeness. Although basic descriptions follow below, more detailed explanations of methods are given where required in the results and interpretation sections.

\section{a) Lapse rate modelling}

Of the 60 datalogger records, 46 sites were chosen which had less than $5 \%$ of missing data. This is a stricter requirement than in many other comparable studies (e.g. $15 \%$ for Blandford et al., 2008) but included enough sites to cover the full elevational and topographical ranges. The lapse rate for all 46 sites was calculated by fitting an ordinary least-squares regression to all temperatures at any one point in time ( $6 \mathrm{~h}$ resolution) and deriving the gradient of the best-fit line. We also calculated the $R^{2}$ so that lapse rates for badly fitting models could be omitted where appropriate.

Subsequently, we recalculated lapse rates for three subsets of data based on high, medium and low elevational 
bands. We divided the sites into three roughly equal categories: low (75-100 m: $n=15)$, medium (100-175 m: $n=16)$, and high elevations (175-330 m: $n=15)$. The $100 \mathrm{~m}$ and $175 \mathrm{~m}$ contours are shown in Figure 1. Lapse rate models were also recalculated for the whole elevational range using only sites with northerly $(n=18)$ and southerly $(n=18)$ aspects. Details of the subdivisions of aspect are given in Table I (column 2).

On the basis of signs of the lapse rates for the low, medium and high groups, we derived an inversion classification. A set of dummy variables $(0: 1)$ were defined which were scored as 1 if the lapse rate was above zero (meaning an increase in temperature with height over this elevational band). The three dummy variables were summed to create a classification (from 0 to 7 ) allowing the examination of the vertical extent/structure of a near surface inversion.

\section{b) Investigation of variation in surface temperatures from free air reanalysis variables}

To study complexity at site level, we then split temperature variation into that driven by synoptic versus that driven by local conditions. We interpolated the $850 \mathrm{mb}$ temperature from NCEP/NCAR reanalysis R1 in the horizontal plane to the geographical position of the surface sites (in a broadly similar way to Pepin and Seidel, 2005) and used this horizontally interpolated temperature as the first predictor of surface temperature. The residuals from this model were then modelled at two contrasting sites; the summit of Jesnalvarra (Jec; $330 \mathrm{~m}$ ); and the bottom of the incised valley of Tsarsejokordsi (94 m; Wind2) in Figure 1. Both regression models used a stepwise approach. In this way the predictability of the decoupling of surface conditions from the general synoptic flow was assessed.

\section{c) Assessing the representativeness of individual sites}

Because the decoupling is temporally and spatially variable, we asked how representative of the broad area individual sites were in terms of their temperature regime. We employed a method based on Orlandini et al. (2006) to assess the representativeness of each station in comparison with all other sites. We used the median absolute deviation (MAD) statistic (rather than the mean as in their research) in acknowledgement of the fact that our earlier results showed that the distribution of lapse rates and of individual temperatures was not normal. The median absolute yearly deviation (MAYD) statistic was calculated by first determining the MADs for each site from the median value across all sites:

$$
\text { median absolute deviation }(\mathrm{MAD})=\left|T_{\mathrm{i}}-T_{\text {median }}\right|
$$

The MAD values were then averaged by month, and these 12 monthly MAD values were then averaged to give the MAYD statistic for each site. This was used to assess which sites were the best to capture a large part of the local spatial heterogeneity, and to assess the extent to which the Kevo weather station adequately performs this task. Lower MAYD values indicate a more representative site (Orlandini et al., 2006).

\section{Results and analysis/interpretation}

\subsection{Lapse rate modelling (whole valley)}

Clustered box plots of 6-h lapse rates by month for the full 46 stations (Figure 3(a) and (b)) show clear seasonal and diurnal patterns. Only rates for models with $R^{2}>0.5$ are shown in these graphs (57\% of cases). Separate panels are given for the winter and summer halves of the year. Although, negative lapse rates (decrease of temperature with elevation) are common at any season, positive values indicating inversion conditions with intensities steeper than $80^{\circ} \mathrm{C} \mathrm{km}^{-1}$ are recorded in mid-winter.

There are changes over the year in terms of whether the seasonal or diurnal cycle is dominant, and these changes are driven by high latitude solar geometry. A seasonal contrast dominates during the periods of polar day (June, July) and polar night (December, January) (centre months in Figure 3) with frequent inversion events during the winter but relatively few in the summer. The lack of insolation during the winter permits a wide range of lapse rates, which are expected to be primarily controlled by cloud cover, wind strength and direction (i.e. synoptic conditions). There is no diurnal signal. In the summer $24 \mathrm{~h}$ sunlight suppresses strong inversion formation and any inversions that do form are weak (predominantly at 0200 FST).

Accepted theory is that calm, clear conditions above the surface experienced in high pressure systems are most likely to lead to intense inversion formation (positive lapse rates; Whiteman et al., 1999; Iijima and Shinoda, 2000) through rapid radiation loss. Thus it is tempting to relate the presence of strong inversions to the synoptic conditions ( $\mathrm{A}-\mathrm{C}$ index representing anticylonicity) and the zonal index (representing air mass). However, the links in this case are often unclear because of a lack of correlation between vorticity and the cloud-free conditions (at any height) required for inversion formation (figure not shown). For much of the year, particularly in winter, the necessity for anticyclonic conditions to create clear skies is weakened because lack of convection means that there are often clear skies under cyclonic conditions as well (particularly in shallow mature depressions common in this area). Low level cloud and formation of fog in situ, which arrests surface cooling further, is also uncommon under any synoptic conditions in winter and spring because of the dry air. In the summer the traditional relationship is more robust. Thus looking at the partial correlation between long term monthly climate data at Kevo meteorological station (January 1962 - December 2008) and the A-C index (Daly et al., 2009) there is a strong control of temperature in summer, but not winter (Table II). Zonal flow becomes more dominant during 


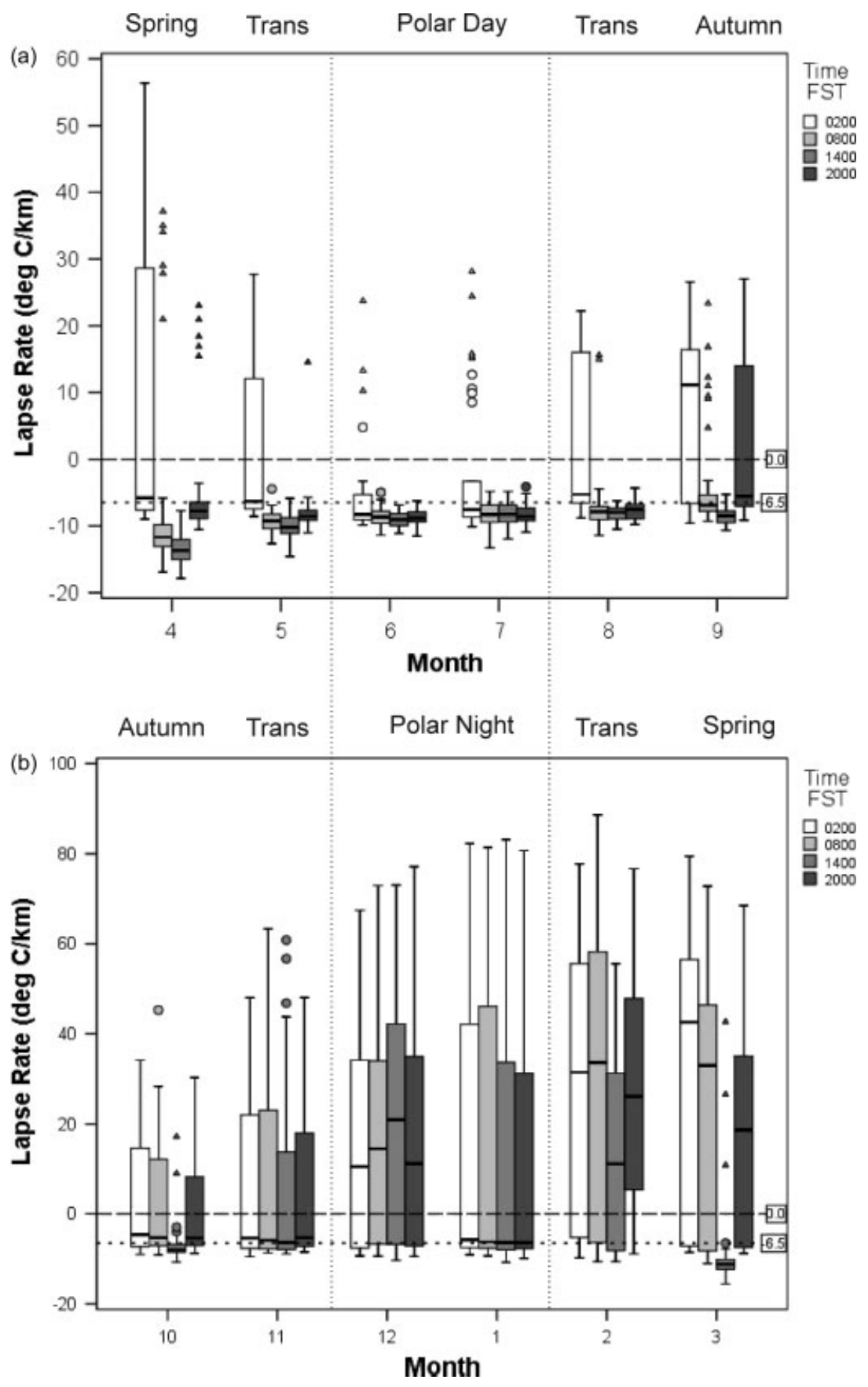

Figure 3. Box plots of $6 \mathrm{~h}$ lapse rates by time of day and month based on 46 stations. Only models with an $R^{2}>0.5$ are shown in these plots (57\% of cases). (a) April through October, (b) November through March.

winter suggesting that air-mass is just as important as vorticity.

During spring and autumn (edges of Figure 3), especially around the equinoxes, the diurnal cycle becomes the major control of lapse rates. Inversions often occur at night (especially 0200 FST) but are eroded during the day. Generally spring has a more extreme diurnal cycle than autumn, aided by deep spring snow cover which encourages intense inversion formation (lapse rates up to $80^{\circ} \mathrm{C} \mathrm{km}^{-1}$ ) at night. These almost always disappear by 1400 FST. September has a similar diurnal cycle but of much lower amplitude. Given, (a) the noon solar elevation at the spring equinox of only $20^{\circ}$ and (b) the high albedo of the snow-covered landscape, this daily dissolution of intense nocturnal inversions in spring is somewhat unexpected from an energy balance perspective. However, daytime humidities are often low (data not shown but measured at most sites). There is minimal transpiration because of lack of vegetation growth and the lack of moisture in the air above the frozen landscape allows a comparison with desert environments. Temperatures generally stay below freezing so there is little or no snow melt during March/early April, minimising latent heat flux and allowing a large proportion of energy to go into sensible heating. This causes rapid temperature changes, rapid inversion formation/dissolution and a 
Table II. Correlations between A-C index, zonal index and temperature/precipitation at Kevo meteorological station (1962-2008). Mmean $=$ mean monthly temperature, Mtmax $/$ Mtmin $=$ mean monthly maximum $/$ minimum temperatures, Mprecip = Mean monthly precipitation.

Partial correlations (AC ctrl by Z, Z ctrl by AC)

\begin{tabular}{lcccccccccccr}
\hline & January & February & March & April & May & June & July & August & September & October & November & December \\
\hline AC & & & & & & & & & & & & \\
Mmean & 0.69 & -0.02 & -0.04 & $0.3^{\mathrm{a}}$ & 0.02 & $0.64^{\mathrm{b}}$ & $0.36^{\mathrm{a}}$ & $0.52^{\mathrm{b}}$ & -0.01 & 0.13 & 0.02 & -0.14 \\
Mtmax & 0.27 & 0.14 & 0.04 & $0.45^{\mathrm{b}}$ & 0.17 & $0.54^{\mathrm{b}}$ & $0.26^{\mathrm{c}}$ & $0.56^{\mathrm{b}}$ & $0.32^{\mathrm{a}}$ & 0.06 & 0.02 & 0.28 \\
Mtmin & -0.06 & -0.13 & 0.02 & 0.09 & $-0.36^{\mathrm{a}}$ & $0.33^{\mathrm{a}}$ & -0.02 & -0.02 & 0.03 & 0.22 & 0.14 & -0.17 \\
Mprecip & $-0.45^{\mathrm{b}}$ & $-0.53^{\mathrm{b}}$ & $-0.38^{\mathrm{b}}$ & -0.21 & $-0.7^{\mathrm{b}}$ & $-0.33^{\mathrm{a}}$ & $-0.46^{\mathrm{b}}$ & $-0.6^{\mathrm{b}}$ & $-0.62^{\mathrm{b}}$ & $-0.59^{\mathrm{b}}$ & $-0.58^{\mathrm{b}}$ & -0.24 \\
Z & & & & & & & & & & & & \\
Mmean & $0.39^{\mathrm{b}}$ & 0.11 & 0.21 & -0.26 & -0.16 & 0.14 & $0.26^{\mathrm{c}}$ & -0.00 & 0.17 & $0.32^{\mathrm{a}}$ & 0.14 & $0.36^{\mathrm{a}}$ \\
Mtmax & $0.47^{\mathrm{b}}$ & 0.19 & $0.26^{\mathrm{c}}$ & 0.2 & -0.41 & -0.01 & 0.06 & 0.18 & 0.06 & $0.33^{\mathrm{a}}$ & -0.03 & $0.49^{\mathrm{b}}$ \\
Mtmin & $0.31^{\mathrm{a}}$ & -0.00 & 0.07 & -0.14 & 0.19 & 0.19 & 0.24 & -0.15 & -0.05 & 0.08 & 0.15 & 0.09 \\
Mprecip & $0.38^{\mathrm{a}}$ & -0.07 & 0.21 & -0.12 & -0.63 & 0.16 & 0.03 & $-0.3^{\mathrm{a}}$ & -0.08 & 0 & -0.03 & -0.04 \\
\hline
\end{tabular}

a Significant at $p \leq 0.05$.

b Significant at $p \leq 0.01$.

${ }^{\mathrm{c}}$ Marginally significant at $p \leq 0.1$.

large diurnal cycle in air temperature at lower elevation sites (Figure 4), sometimes approaching $30^{\circ} \mathrm{C}$ (Clements et al., 2003; Betts, 2011). In autumn this is not the case, with vegetation and open water (in particular the lake) both increasing the latent heat flux, resulting in a more subdued diurnal lapse rate cycle overall, although there is still a slight increase in mean daily temperature range in September driven by comparable solar geometry $(\sim$ day 260 in Figure 4).

Of perhaps the most interest are the four transitional periods between seasons. The first type of transition occurs around February (from winter towards spring) and August (from summer towards autumn). Both these transitions are relatively predictable, because although

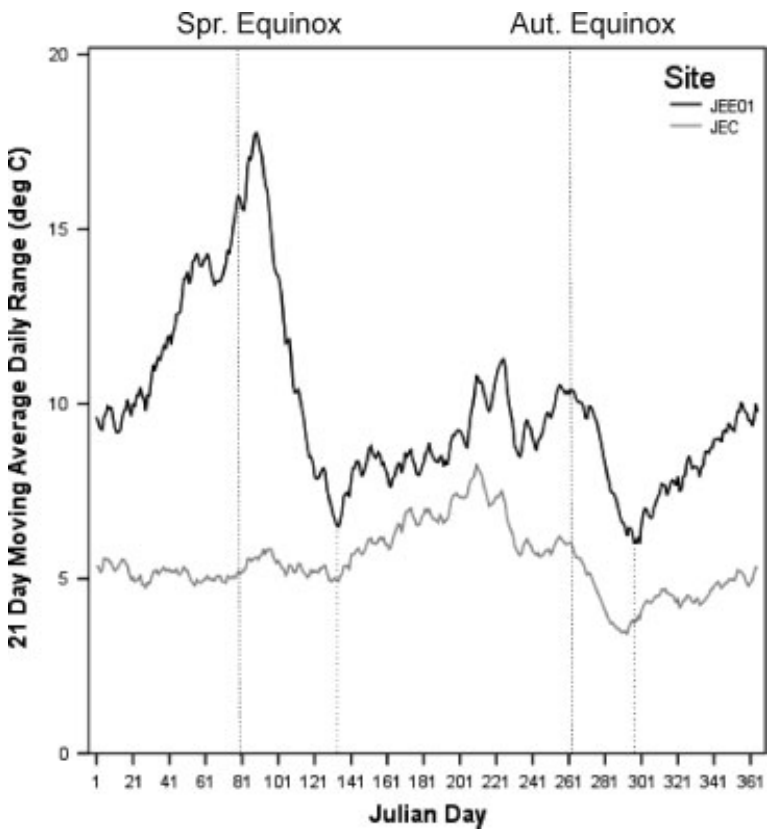

Figure 4. $21 \mathrm{~d}$ moving average mean diurnal temperature range vs. Julian date at (a) JEE01 (lakeside), (b) JEC (summit). day length is changing rapidly, ground cover conditions are fixed (snow cover in February, no snow in August). Lapse rate behaviour gradually changes with diurnal cycles becoming more noticeable (months marked as Trans in Figure 3). The second type of transition occurs in May and November. At these times of year not only is day length changing rapidly but the ground cover is also changing rapidly, with snow and lake ice melt in May and snow build-up and water freeze-up in late October/early November. These surface conditions vary from year to year and so these transitions are much less predictable. Figure 4 shows that during both lake freeze up ( $\sim$ day 290-300) and melt ( day 130-140) (indicated by dotted lines), the mean diurnal temperature range is reduced, especially at the lower elevation sites, a result of enhanced latent heat flux and reduced sensible heating.

Figure 5(a)-(d) concentrates on two periods in more detail, the winter season and the spring/summer transition. Both are of particular interest since they are unique to high latitudes, and contrast with traditional mid-latitude studies (e.g. Clements et al., 2003; Whiteman et al., 2004). For two case studies, time series of lapse rate (grey line) are plotted against changes in cloud cover (dots), as recorded at Kevo meteorological station, and flow strength (black line). Relationships with flow direction and vorticity were much weaker as previously discussed (not shown).

During the polar night (Figure 5(a) and (b)) inversion events are common place and a cold pool can persist for days at a time. Most persistent events are associated with weak flow strength and lack of cloud. However, flow strength is the strongest control. While formation is often gradual, inversion destruction is often extremely rapid and mechanically driven. Understanding the detailed trigger mechanisms for destruction is an area for further research. 
The spring/summer transition is also complex (Figure 5(c) and (d)). In spring the strongest diurnal lapse rate cycles are accompanied by weak flow strength and lack of cloud cover. The strength of the sun is such that inversions are nearly always destroyed by 1400 FST. Daytime lapse rates are even steeper than those during summer, especially during April, probably due to the influence of surface albedo, as well as the concentration on daytime sensible heating. On lower and midslopes the lower albedo of the pine forest warms the air, whereas on the relatively birch dominated or vegetation free snow-covered upper slopes (particularly above the pine limit - about $200 \mathrm{~m}$ ) a high albedo helps to keep temperatures low, thus steepening daytime lapse rates under conditions of strong insolation. At night this effect disappears and the snow covered landscape allows the rapid redevelopment of cold air drainage and inversion events.

As the transition to $24 \mathrm{~h}$ daylight continues in late April and May lapse rates become more consistent with very few inversion events. Normally by the beginning of June the snowpack has melted but for a few isolated snow patches, and the lake is free of ice and begins to act as a heat buffer, regulating temperatures in the valley bottom. The lake effect, combined with the disappearance of snow albedo forcing, means that lapse rates during the summer months are less steep than those for daylight hours in March and April. The inversions that do form on a micro-scale are relatively weak and are due to the topographical shading of the incised valley area as
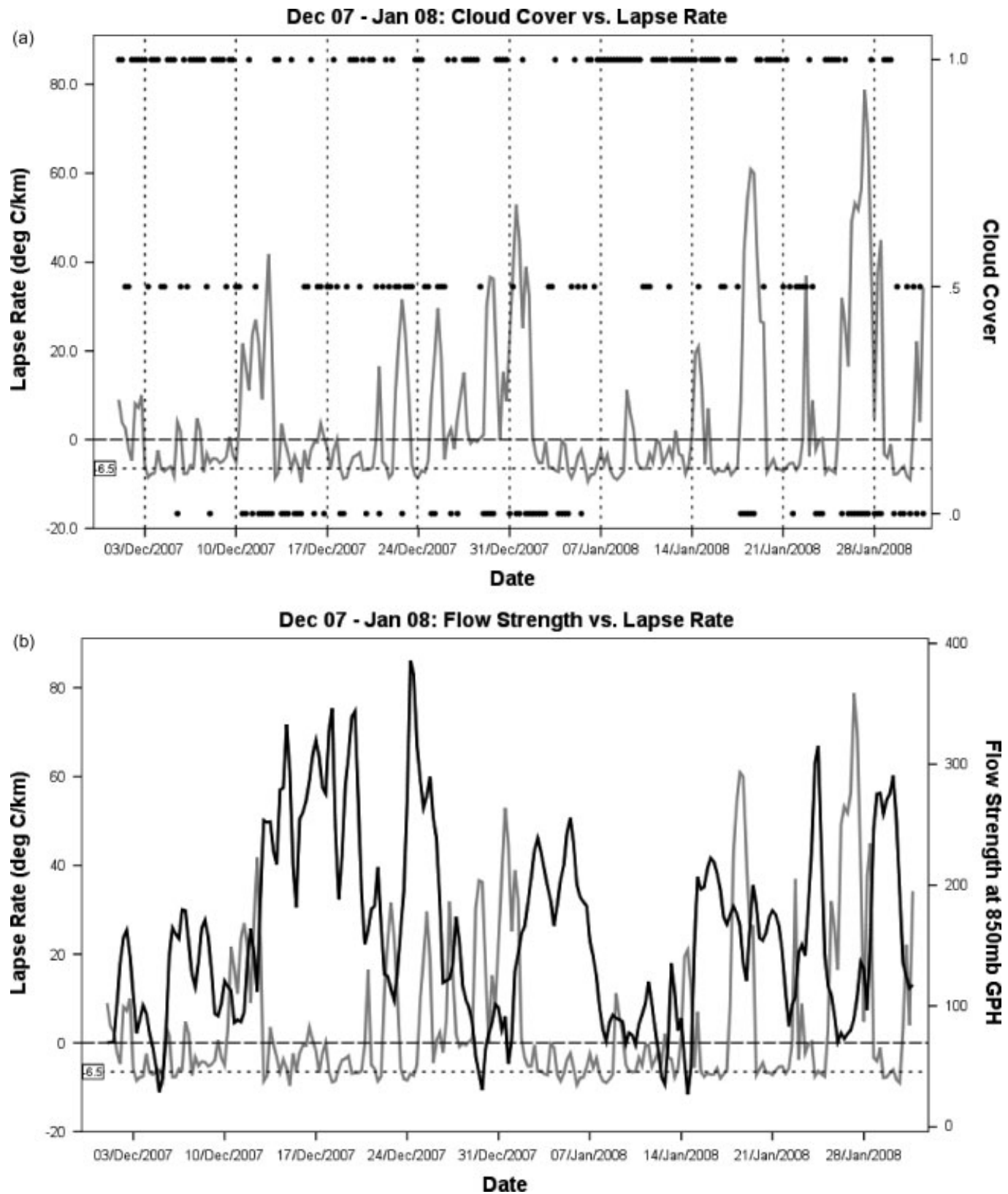

Figure 5. Case studies of lapse rate behaviour. The data points are at $6 \mathrm{~h}$ intervals. The grey line represents the lapse rate (inversions are positive): winter December 2007-January 2008, (a) cloud cover (individual markers) (b) flow strength (black solid line): spring transition March-April 2008, (c) cloud cover, (d) flow strength. Cloud cover has been aggregated into three categories $(0=0-2,0.5=3-5$, and $1=6-8$ oktas). 

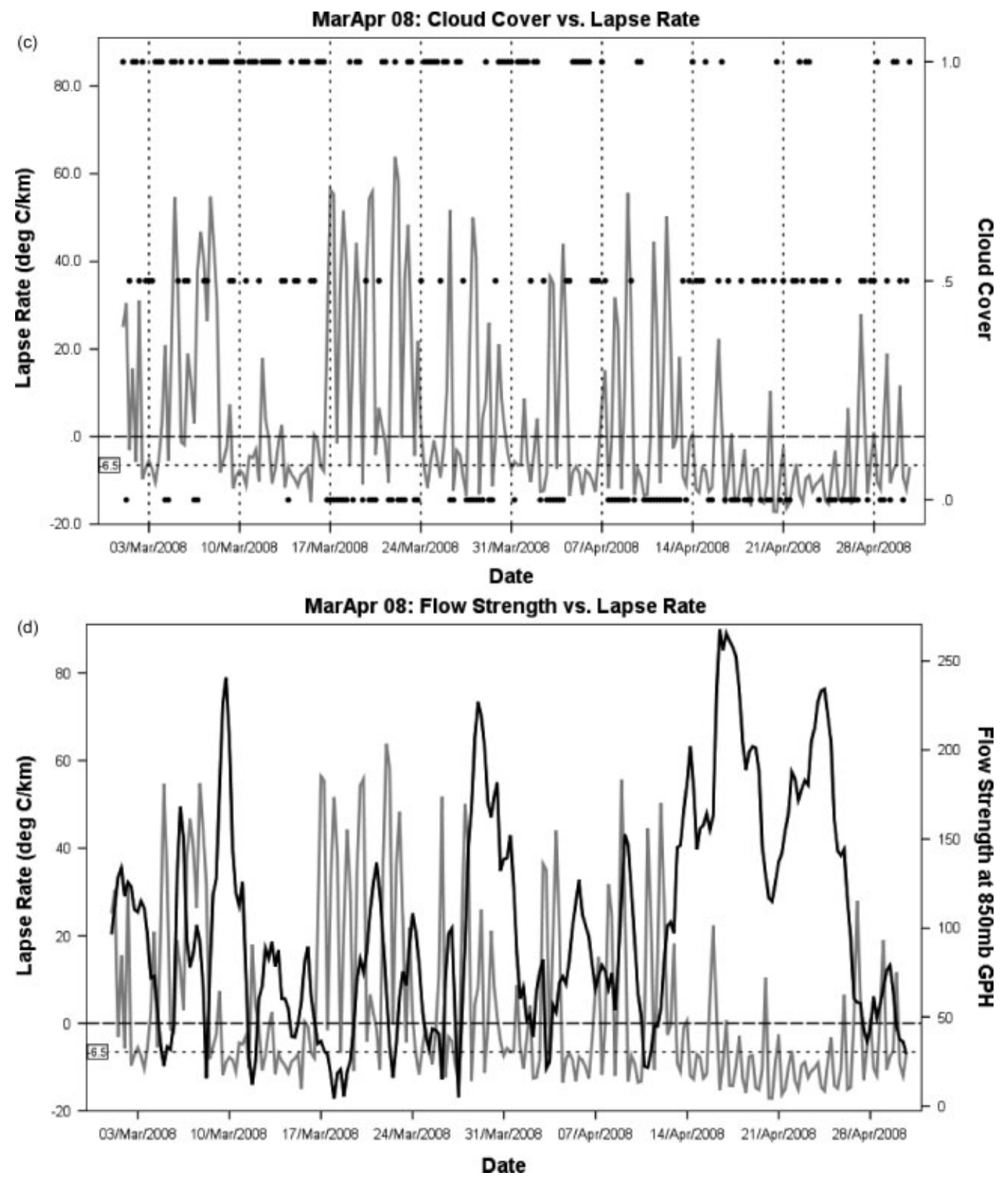

Figure 5. (Continued).

the sun skims low over the northern horizon during the 'night'.

The influence of aspect on lapse rates was examined by rerunning models for the full elevational range but using sites with only northerly $(n=18)$ or southerly $(n=18)$ aspects. General seasonal and diurnal patterns are broadly similar to the main model shown in Figure 3, and any differences are subtle (not shown). Aspect effects were more evident during the spring and summer months.

\subsection{Detailed vertical structure}

\section{a) Model performance}

To examine vertical temperature structure within our study area in more detail, lapse rate models were calculated for subsets of stations, dividing them into three elevational bands with broadly equal numbers $(75-100 \mathrm{~m}$;
$100-175 \mathrm{~m}$ and $175-330 \mathrm{~m})$. Unsurprisingly the bottom band shows the poorest models because of the relatively small elevational range combined with the large variety of surface types (Figure 6).

In the middle elevational band $R^{2}$ is only slightly higher. It is in this band that aspect differences become most critical and can reduce model fit. Most sites are on the often steep valley sides. The best models for this band occur during the winter and summer when the diurnal influence is low. The models are particularly poor around the spring equinox, probably due to snow cover and treeline effects accentuating aspect effects. Without snow cover around the autumn equinox the drop in model performance is tempered somewhat, but is still evident.

The best models are obtained for the highest elevational band. The change in environment between the top and bottom of this zone is marked, from sheltered 


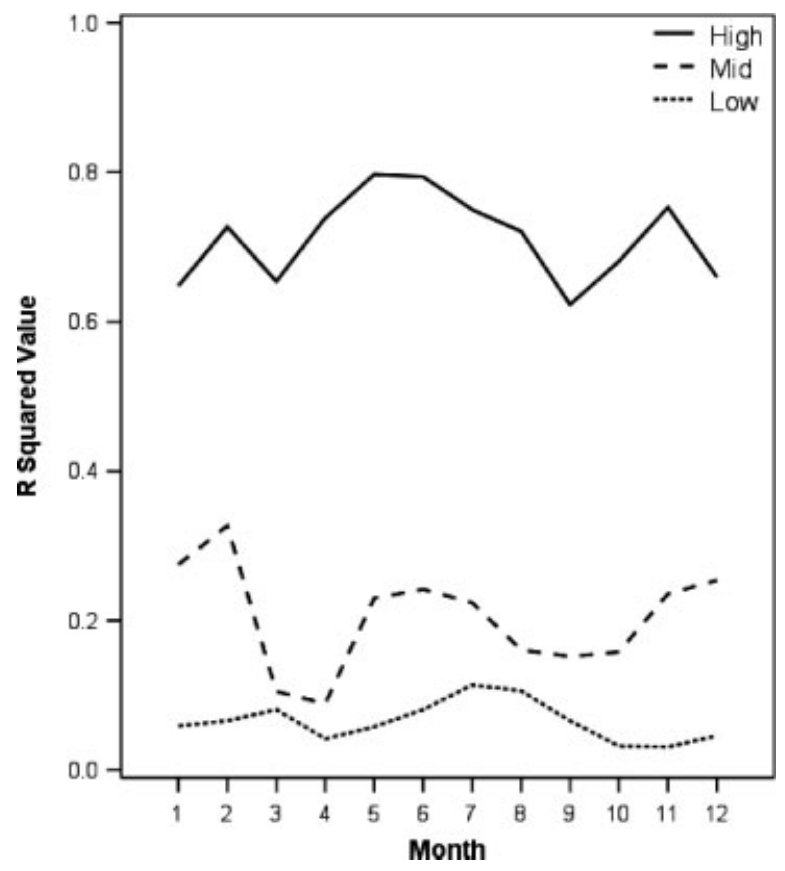

Figure 6. Summary plot of the lapse rate gradient median $R^{2}$ by elevation band.

forested slopes, to open treeless tundra. Thus temperature is predominantly controlled by elevation rather than aspect or surface type.

\section{b) Lapse rates}

Figure 7 plots diurnal changes in lapse rate for the three elevational bands for three groups of months, (a) winter when there is limited diurnal forcing, (b) spring when diurnal effects peak but the lake is still frozen and (c) summer when the lake is unfrozen. In the low elevation range there is a mixture of lakeside locations, forested sites and grassy clearings, and distance from the lakeshore or rivers can become a critical influence on temperature through local advective effects, particularly in the warmer half of the year. The influence of the lake cooling means reduced daytime lapse rates in summer for the lowest elevation band where the lowest sites are on the lake shore. The effect of the lake on low elevation lapse rates is clearly seen within group 3 causing reversal of the diurnally induced ' $\mathrm{V}$ ' pattern evident during all other times of year and elevational bands.

This analysis shows that it is easiest to model temperatures at the higher elevations, and it is on the slopes and in valley bottoms where microclimate effects other than elevation become more distinct. Thus a simple downward extrapolation of temperature based on lapse rates at higher elevations will be less reliable the lower one goes.

\subsection{Inversion classification}

The signs of the lapse rates in the three tier lapse rate model (using three elevational bands) described above were used to create an inversion classification which describes the vertical extent of inversions (Figure 8). This

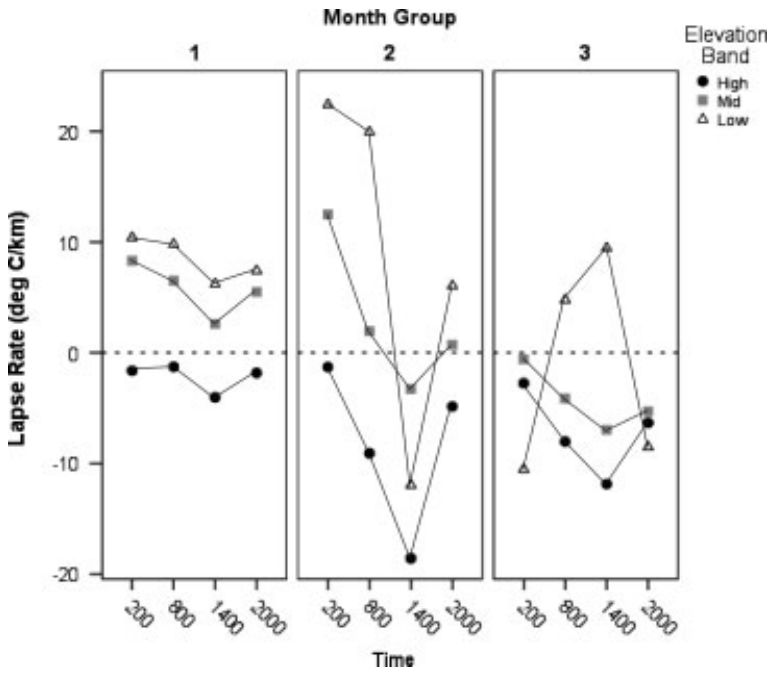

Figure 7. Summary gradients for lapse rate models for high (330$175 \mathrm{~m}, 15$ sites), medium (175-100 m, 16 sites) and low (100-75 m, 15 sites) elevation bands. Lapse rates are grouped by months with similar characteristics $[1=\mathrm{NDJF}$ (winter), $2=\mathrm{MA}$ (spring), $3=$ MJJASO (summer)]. Lapse rate values are the average of the medians for each month by time with the group.

classification supports previous findings (Pepin et al., 2009). Inversions extending all the way up from the valley floor at least to the highest summits or above (class 7) are most common in winter (between November and March). Surface based low level inversions (class 1) are the most common in summer, possibly because of the stabilizing and cooling influence of Kevojarvi at the lowest elevations (Figure 7, group 3). Other inversion classes are rare, but a medium level inversion (class 3) is fairly common in the winter half of the year, usually as a transition type between low level and full inversions.

5.5. Prediction of surface temperatures from free air reanalysis variables

To examine whether the variable lapse rates and the formation of intense inversions outlined above have consequences for downscaling from larger scale free-air temperatures in this region, models are derived to predict surface temperatures from free-air equivalents.

Using a simple linear regression with horizontally interpolated $850 \mathrm{mb}$ temperature as the predictor, the free-air temperature explained $72.4 \%$ of the variance of surface temperature at Jec (the highest site) but only $62.1 \%$ at Wind2 (a site in the bottom of the Tsarsejoki valley). In general, higher elevation sites had higher $R^{2}$ (Figure 9). The sites with outlying low values are due to local issues with missing or unreliable data and these sites were excluded from our previous analyses for this reason. Even on the exposed alpine heaths factors act to decouple the surface temperature from the free air equivalent on certain occasions. This in turn suggests that the inversions extend higher than our highest site and develop on a larger scale than our valley system. The range of $62-72 \%$ variance explained by the $850 \mathrm{mb}$ free-air temperature is notably less than the $70-80 \%$ of surface temperature variance explained by 


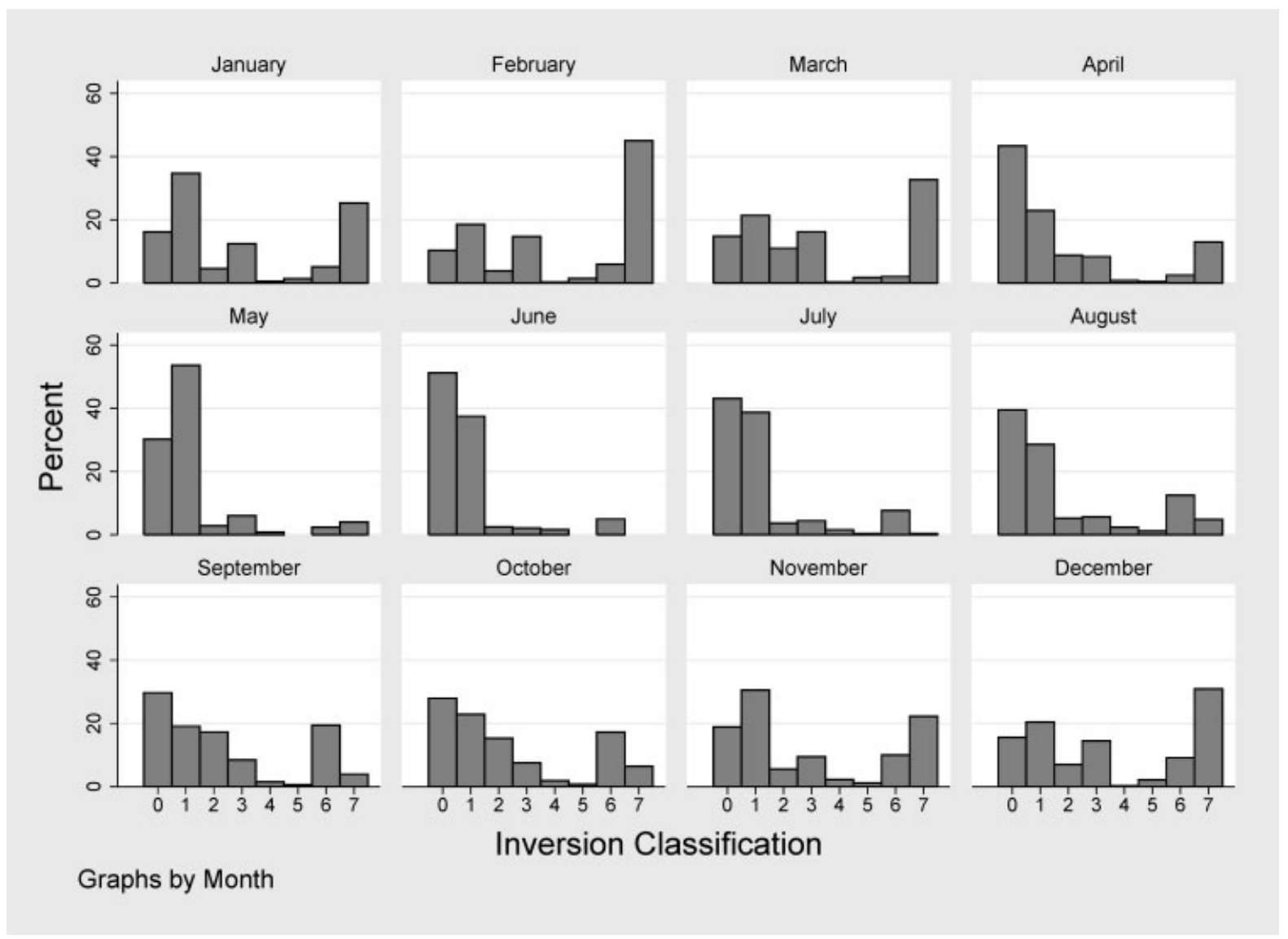

Figure 8. Histograms showing the frequency of various inversion classifications for each calendar month. Inversion type: 0 none, normal conditions, 1 low, 2 mid, 3 low \& mid, 4 high, 5 low \& high, 6 mid \& high, and 7 full inversion.

regional temperature patterns modelled by Dobrowski et al. (2009) who performed a similar analysis, albeit at a larger scale at mid-latitudes, in the Lake Tahoe region of California, USA.

Attempts to explain the variance in the residuals from this simple model were made using stepwise regression. Successful attempts involve adding a large number of

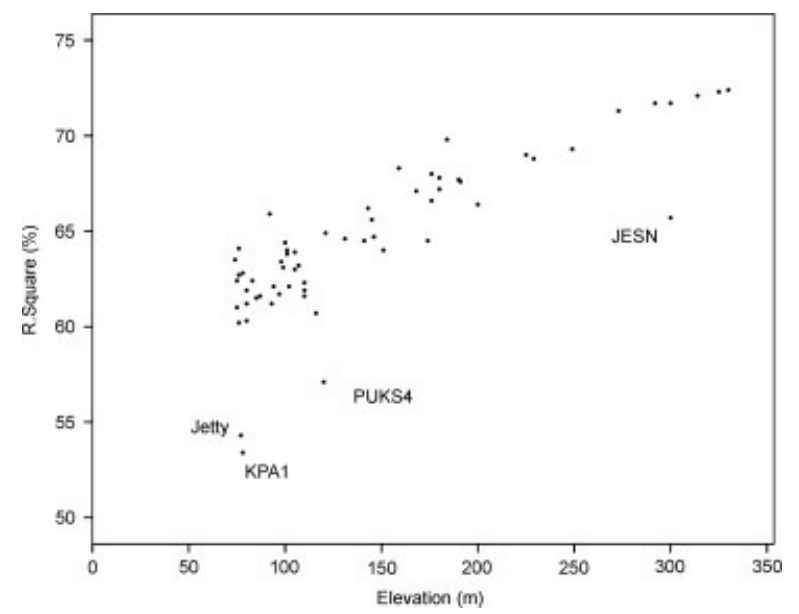

Figure 9. $R^{2}$ versus elevation for surface temperatures at a selection of stations when predicted from interpolated $850 \mathrm{mb}$ free-air temperature alone. variables. Although, the (temporally variable) height difference between the interpolated $850 \mathrm{mb}$ temperature and the surface elevation is a significant factor in explaining the residual variance, it alone does not explain a significant proportion. Nearly half of the residual variation at Jec and a third of the residual variation at Wind2 can be modelled by using dummy variables to divide the data seasonally and by time of day (Table III). The weaker model performance for site Wind 2 demonstrates the particular difficulty of predicting winter temperatures during inversion conditions, specifically the strength of the inversions. January at 0000 GMT (0200 FST) was the base category. Interactions between time of day and month are significant from February to October, but not during the polar night. This shows that decoupling has both seasonal and diurnal controls, with interactions between the two which are to some extent predictable.

\subsection{Assessing the representativeness of individual} sites

Using the MAYD statistic, Table IV shows the top ten most representative sites of our whole study area (for median, maximum and minimum daily temperatures) along with the position of Kevo Meteorological station in the rankings (even if not in the top 10). Figure 10(a) (median of all temperatures) demonstrates that overall sites between $100 \mathrm{~m}$ and $150 \mathrm{~m}$ elevation are the 
Table III. Significant variables used to explain the residual variance of surface temperature at Jesnalvarri summit (Jec) after prediction from interpolated free air temperatures.

\begin{tabular}{lcc}
\hline & Hilltop (JEC) & Valley (Wind2) \\
\hline$R^{2 \mathrm{a}}$ & $72.4 \%$ & $62.1 \%$ \\
Residual modelling $R^{2 \mathrm{~b}}$ & $45.8 \%$ & $34.6 \%$ \\
Overall $R^{2}$ & $85.0 \%$ & $75.2 \%$ \\
\hline
\end{tabular}

${ }^{\text {a }}$ Predictor $=$ Horizontally interpolated $850 \mathrm{mb}$ level temperature.

${ }^{\mathrm{b}}$ Predictors $=$ month, time, interactions, westerly flow strength, southerly flow strength, dGPH $850 \mathrm{mb}$.

most representative of the study area. These sites tend to have westerly or easterly aspects, rather than more extreme northerly or southerly aspects (Table IV with reference to Table I). Deviation of the maximum temperatures (Figure 10(b)) shows no strong pattern. However, for minimum temperatures (Figure 10(c)) the influence of intense inversion conditions in winter means that temperature variability at the lower elevation sites is much greater (as seen in Figure 4). As there are relatively more sites at low elevation, the higher elevation sites are perceived to show greater deviation with respect to minimum temperatures. Although our sites are representative of the terrain sampled, the representativeness of individual sites is a statistical artefact, dependant on site population and location. For a map of the sites (with station codes) refer to Figure 1.

It is important to realise that this analysis determines the representativeness of each station of the whole valley area we have measured, and not the area outside or beyond it. By comparing each site with all other sites we assume that the accumulated mass of sites is the 'best' representation of the valley system. By weighting each site equally in the accumulated mass we are also assuming that we have covered the valley system evenly (in terms of including all possible aspects, elevations, degrees of topographic exposure and slope). Our original sampling strategy was based on this premise and preliminary chi-square analyses confirmed this (see section 4.1).

Despite, or possibly because of, the strong decoupling in the valley system, the Kevo station comes out well, particularly for maximum temperatures where the station is second out of 61 sites in terms of broad representativeness. Thus the station represents the area which has been instrumented well. This is not necessarily the wider region which includes much more extensive arctic tundra similar to that around the highest elevation sites in our study.

\subsection{Summary}

Lapse rate modelling in the case of northern Finland shows that incised topography combined with a complex high latitude seasonal/diurnal interaction allows the development of extreme contrasts of lapse rates throughout the year. The seasonal influence, strongest in the periods of polar night and day, could be thought of as being out of phase with the diurnal pattern which is strongest around the spring and autumn equinoxes. Thus changing solar geometry, aligned with surface changes (i.e. snow/lake melt and freeze up) are dominant influences on lapse rate climatology. This is recognised by Zhenlin et al. (2011) who develop a lapse rate model partly based on solar geometry for Abisko, Sweden - a broadly similar environment.

\section{Discussion}

Our data have demonstrated the development of intense temperature inversions within Kevo valley which mean that lapse rates bear no relation to those in the freeair or on a regional scale. Thus it is unhelpful to make direct comparisons of our findings with other studies on larger scale lapse rates (Pepin et al., 1999; Rolland, 2003; Marshall et al., 2007; Blandford et al., 2008; Minder et al., 2010; Cullen and Marshall, 2011).

However, useful comparisons can be made with smaller scale studies. The seasonal and diurnal patterns

Table IV. The top 10 representative stations within our study area for daily median, maximum and minimum temperatures using the method of Orlandini et al. (2006). In bold, the position of Kevo meteorological station in the rankings is also listed along with the least representative station (bottom line).

\begin{tabular}{lcccccccc}
\hline Rank & MAYDmed & Site & Rank & MAYDmaxmd & Site & Rank & MAYDminmd & Site \\
\hline 1 & 0.242 & lasse2 & 1 & 0.112 & tsae2 & 1 & 0.079 & kevhs \\
2 & 0.253 & tsie1 & $\mathbf{2}$ & $\mathbf{0 . 1 3 6}$ & KevoSta & 2 & 0.176 & pukw2 \\
3 & 0.258 & tsae1 & 3 & 0.138 & lasse1 & 3 & 0.215 & jess0 \\
4 & 0.281 & jese4 & 4 & 0.143 & tsacol & 4 & 0.240 & puks3 \\
5 & 0.290 & pukw2 & 5 & 0.148 & tsaw & 5 & 0.246 & tsae1 \\
6 & 0.292 & tsiw2 & 6 & 0.185 & tsiw2 & 6 & 0.265 & jumb2 \\
7 & 0.294 & lasse1 & 7 & 0.191 & puks7 & 7 & 0.265 & kevv2 \\
8 & 0.305 & kevv2 & 8 & 0.203 & jese3 & 8 & 0.275 & tsan1 \\
9 & 0.308 & kpa2 & 9 & 0.215 & kevv1 & 9 & 0.281 & tsan0 \\
10 & 0.313 & jese3 & 10 & 0.217 & tsan2 & 10 & 0.311 & kpa2 \\
$\mathbf{1 5}$ & $\mathbf{0 . 3 4 2}$ & KevoSta & - & - & - & $\mathbf{2 1}$ & $\mathbf{0 . 4 2 6}$ & KevoSta \\
$\mathbf{6 1}$ & $\mathbf{0 . 9 9 6}$ & jec & $\mathbf{6 1}$ & $\mathbf{1 . 2 3 7}$ & jetty & $\mathbf{6 1}$ & $\mathbf{4 . 2 5 8}$ & jese8 \\
\hline
\end{tabular}



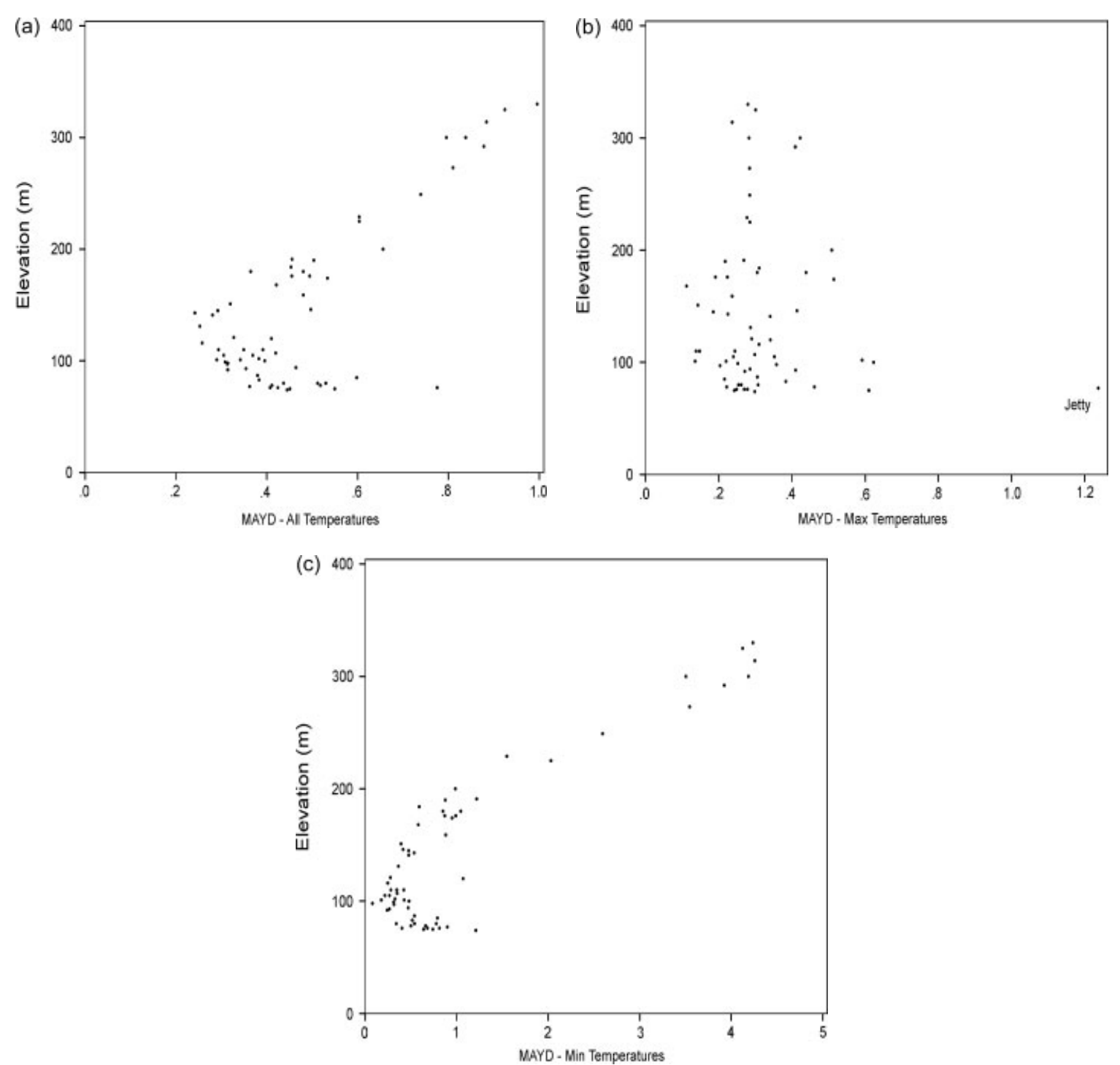

Figure 10. Site representativeness using the MAYD statistic (based on Orlandini et al., 2006) plotted against elevation, based on (a) all temperatures, (b) maximum temperatures and (c) minimum temperatures.

in inversion occurrence, although not the same as in midlatitudes, follow a more extreme version of these patterns. For example, Daly et al. (2009) found that in winter, synoptic conditions often overrode any daytime heating signal. Persistent inversions in our dataset in the polar night are a more extreme example of this process. Bolstad et al. (1998) (southern Appalachians, $\sim 35^{\circ} \mathrm{N}$ ) reported local monthly maximum temperature lapse rates of between -4 (January) and $-10^{\circ} \mathrm{C} \mathrm{km}^{-1}$ (April), with the highest rates in spring and the lowest in winter, and monthly minimum lapse rates between +3.8 (October) and $-5.8^{\circ} \mathrm{C} \mathrm{km}^{-1}$ (August), showing more variability during winter than in summer, and more overall variability than maximum temperature lapse rates. Taking 1400 FST and 0200 FST as proxies for maximum and minimum temperature lapse rates, respectively (from Figure 3) we observed broadly similar patterns. However, our lapse rate values are much more extreme with monthly maximum lapse rates between +18.8 (December) and $-13.4{ }^{\circ} \mathrm{C} \mathrm{km}^{-1}$ (April) and monthly minimum lapse rates between +32.5 (March) and $-5.8^{\circ} \mathrm{C} \mathrm{km}^{-1}$ (June). Lookingbill and Urban (2003) (Oregon Western Cascades, $\sim 44^{\circ} \mathrm{N}$ ) noted July mean, maximum, and minimum lapse rates of $-4.5,-7.0$, and $-3.8^{\circ} \mathrm{C} \mathrm{km}^{-1}$, respectively. For our study area mean July lapse rate values were -6.8 , -8.3 , and $-2.2{ }^{\circ} \mathrm{C} \mathrm{km}^{-1}$, respectively. However, if we report median values then the values, $-8.2,-8.2$, and $-7.6^{\circ} \mathrm{C} \mathrm{km}^{-1}$, respectively, are very different again due to the skewed distribution of the data.

Individual $6 \mathrm{~h}$ lapse rates in our study range from $-17.2^{\circ} \mathrm{C} \mathrm{km}^{-1}$ to $+88.6{ }^{\circ} \mathrm{C} \mathrm{km}^{-1}$, although individual monthly lapse rates (mean temperatures) range from $-7.4^{\circ} \mathrm{C} \mathrm{km}^{-1}$ (May 2008) to $+26.9^{\circ} \mathrm{C} \mathrm{km}^{-1}$ (February 2010). In summer, the widely cited generic environmental lapse rate value of $-6.5^{\circ} \mathrm{C} \mathrm{km}^{-1}$ (Barry and Chorley, 1987) is broadly similar to our mean measurements (MJJA range of means -4.7 to $-8.0^{\circ} \mathrm{C} \mathrm{km}^{-1}$ ). For comparison median values for the summer months are steeper, ranging from -7.4 to $-8.8^{\circ} \mathrm{C} \mathrm{km}^{-1}$. Therefore predictions based on the $-6.5^{\circ} \mathrm{C} \mathrm{km}^{-1}$ lapse rate could 
Table V. Summary of potential impacts of long term climate changes on local lapse rates.

\begin{tabular}{|c|c|c|c|c|}
\hline Season & Time of day & Factor change & Consequence & lapse rate influence \\
\hline Winter & All & $\begin{array}{l}\text { Stronger zonal flow } \\
\text { More cyclonic flow }\end{array}$ & $\begin{array}{l}\text { Increased cloud cover } \\
\text { and mixing } \\
\text { Reduced inversion } \\
\text { intensity }\end{array}$ & More warming in valley \\
\hline Summer & All & $\begin{array}{l}\text { Cloud+, Moisture+, } \\
\text { AC- }\end{array}$ & $\begin{array}{l}\text { Reduced inversion } \\
\text { intensity }\end{array}$ & More warming in valley \\
\hline $\begin{array}{l}\text { Freeze-up (later, } \\
\text { November to December) }\end{array}$ & All & $\begin{array}{l}\text { Stronger zonal flow } \\
\text { More cyclonic flow }\end{array}$ & $\begin{array}{l}\text { Reduced inversion } \\
\text { intensity }\end{array}$ & More warming in valley \\
\hline \multirow[t]{2}{*}{$\begin{array}{l}\text { Melt (earlier, May to } \\
\text { April) }\end{array}$} & Day & $\begin{array}{l}\text { Less snow - earlier } \\
\text { melt, Less snow }\end{array}$ & $\begin{array}{l}\text { Increased latent heat } \\
\text { flux, decreased albedo } \\
\text { effect }\end{array}$ & Less warming in valley \\
\hline & Night & & $\begin{array}{l}\text { Latent heat release on } \\
\text { refreezing }\end{array}$ & $\begin{array}{l}\text { More warming in valley } \\
\text { (dominant factor). } \\
\text { Overall effect is to } \\
\text { reduce the magnitude of } \\
\text { the lapse rate cycle }\end{array}$ \\
\hline
\end{tabular}

be wildly inaccurate if the purpose were to reconstruct instantaneous meteorological observations. When mean monthly temperatures are the focus, the problem is more serious in winter than in summer. An error of over $30{ }^{\circ} \mathrm{C} \mathrm{km}^{-1}$ in lapse rate (such as in February 2010) would lead to an over prediction of mean valley temperatures by $7.5^{\circ} \mathrm{C}$ based on a $250 \mathrm{~m}$ downward extrapolation!

Some palaeoclimate proxies (e.g. chironomids and diatoms) are typically situated in depositional landscapes which preferentially include valley bottoms or depressions. Because these are particularly prone to cold air drainage, the lapse rate problem is especially relevant, although reconstructing summer temperatures (most common) is less problematic than annual means (which include winter).

In this location, the local temperature field shows a complex evolution driven by synoptic variation superimposed upon the astronomical calendar. The implications of this for potential climate change are summarised in Table V. The solar cycle is fixed but synoptic and surface conditions are not. Therefore the juxtaposition of synoptics and surface characteristics (e.g. snow and ice melt) with the astronomical calendar may change, with important consequences for lapse rates.

In the polar night we have shown synoptic controls to be the main lapse rate influence. Most climate models suggest an increasing westerly flow in northern Europe in winter and a strengthening storm track further east into the European continent (Jylhä et al., 2004). Such changes would therefore intensify warming rates in valley bottoms because intense inversions would become less frequent under stormier conditions (stronger flow strength, more cloud cover). During the summer half of the year lapse rate changes associated with a stronger storm track would be less certain, since local effects (e.g. aspect and lake effects) are also important.
Other significant changes would occur as a result of land surface changes being shifted to other times of year, with a reduced snow season (Lemke et al., 2007), earlier snow melt in spring and later freezeup in autumn (Hyvärinen 2003; Moberg et al., 2005). It is unclear whether snow depth in the core of the winter would increase or decrease in the north of Finland because warmer, wetter winters could bring more snow, at least in the short term (BACC, 2008). If freeze-up were to be delayed until late November or December, the character of this transition may change. Changes in solar geometry due to the time shift will be minimal because during the current freeze up (late October or November) solar input is already negligible. The key to understanding possible temperature pattern changes therefore will be interactions between surface freeze-up and larger scale synoptic climatology. Feedbacks between the North Atlantic storm track and surface ice/snow cover build up in autumn are likely to be critical but this is an area of uncertainty in scientific knowledge.

On the other hand, solar geometry is more critical in spring. By the time the current snow melt occurs the diurnal cycle is reducing in importance (late May) and melt is almost continuous (and therefore often rapid). With earlier snow/ice melt in April the diurnal cycle in melt would become more relevant. The current strong diurnal lapse rate cycle common in spring would likely be reduced if melt was earlier. First, any elevational albedo effect (which steepens current daytime rates through increasing albedo preferentially above treeline) would be reduced as snow melts earlier. Second, latent heat would be absorbed during the melt process during daytime especially in low lying areas (reducing temperatures). Conversely, at night increased refreezing will release latent heat into the valley system (steepening night time rates). These diurnal influences on melt (currently weak) will become much more important if the snow/ice break-up moves earlier in the year. Since intense overnight inversions currently 
more than compensate for the daytime lapse rate steepening in March/April, the overall effect on lapse rates of an earlier melt is again likely to be amplified warming in valley bottoms.

A more subtle land surface change may occur later in the summer, when the landscape may become drier (because of earlier snow melt). Under such a scenario, inversion formation could become stronger later in the season (as a result of decreased latent heat flux), particularly in late August and September when current diurnal effects start to strengthen again (Figure 4). This would act to depress overall warming in valley bottoms. However, this is very uncertain, particularly because most scenarios suggest increased summer rainfall and convection which would compensate for earlier snow melt (Jylhä et al., 2004), and also because there will still be large bodies of open water present well into autumn.

\section{Conclusions}

Free-air lapse rates as modelled in GCMs have little relevance for much of the year in this region. Intense inversion formation and strong and persistent surface decoupling of the temperature signal is a significant feature of the current climate. However, most of the expected land surface changes in the Arctic will probably act to decrease inversion formation and hence magnify warming in valley bottoms compared with the landscape as a whole (Table V). Where opposing effects arise during the day and night, it is likely that night time changes will be more significant in terms of influencing mean temperatures, as the negatively skewed distribution of current lapse rates confirms. The enhanced warming at lower elevations which would result would have important consequences for many ecological processes. For example the moth Epirrita autumnata which causes birch defoliation is killed by low temperatures around $-35.5^{\circ} \mathrm{C}$ in winter. Such low temperatures occur only in valley bottom locations as a result of intense temperature inversion formation (Virtanen et al., 1998; Jepsen et al., 2008; Ammunét et al., 2011). Already the warming climate has allowed the winter moth Operopherta brumata to outbreak in to more continental northern Finland from the milder northern coast of Norway (Ammunét et al., 2010). Freezing of lakes is primarily controlled by valley temperatures which are decoupled from free-air changes above. Enhanced warming in such locations would thus have strong environmental consequences which could not be predicted from a general consideration of broad regional scale changes.

Although this study has quantified in detail the behaviour of the temperature structure in a small area $\left(\sim 20 \mathrm{~km}^{2}\right)$ around Kevo Subarctic Research Station, there is no guarantee that all other valley systems will be the same. Thus further research is required to examine whether the results can be extrapolated to a broader spatial area. A comparative study is already being developed around Abisko station in Sweden, where the topographic scale is much larger, but the broad climate and astronomical setting (latitude) is similar. The meteorology of inversion formation and dispersal (the latter is often extremely rapid) requires further study, particularly in winter when dynamical influences override radiation balance. It is clear that continued detailed field measurements along with modelling are essential to understand climate complexity in sub-Arctic landscapes, and hence make realistic predictions about future changes in such environments.

\section{Acknowledgements}

The research leading to these results has received funding from two European Community Grants:

1) Research Infrastructure Action under the FP6 "Structuring the European Research Area" Programme, LAPBIAT (RITA-CT-2006-025969) for the initial project set up and

2) INTERACT (grant agreement No 262693) under the European Community's Seventh Framework Programme.

The authors also acknowledge the support of Metsähallitus for granting permission to work in the area, the staff at Kevo Subarctic Research Station for their continuing support and help with the field logistics, and to the University of Portsmouth students who have contributed to the fieldwork over the years.

\section{References}

ACIA. 2004. Impacts of a Warming Arctic, Arctic Climate Impact Assessment. Cambridge University Press: Cambridge.

Ammunét T, Heisswolf A, Klemola N, Klemola T. 2010. Expansion of the winter moth outbreak range: no restrictive effects of competition with the resident autumnal moth. Ecological Entomology 35: 45-52, DOI: $10.1111 / \mathrm{j} .1365-2311.2009 .01154 . x$.

Ammunét T, Klemola T, Saikkonen K. 2011. Impact of host plant quality on geometrid moth expansion on environmental and local population scales. Ecography. DOI: 10.1111/j.16000587.2011.06685.x.

Armbruster WS, Rae D, Edwards ME. 2007. Topographic complexity and biotic response to high-latitude climate change: variance is as important as the mean. In Arctic-Alpine Ecosystems and People in a Changing Environment, Ørbæk JB, Kallenborn R, Tombre I, Hegseth EN, Falk-Petersen S, Hoel AH. (eds). Springer Verlag: Berlin, 105-122.

Ashcroft MB. 2010. Identifying refugia from climate change. Journal of Biogeography 37: 1407-1413.

Autio J, Heikkanen O. 2002. The climate of northern Finland. Fennia 180(1-2): 61-66.

Ashcroft, MB. 2010. Identifying refugia from climate change. Journal of Biogeography 37: 1407-1413, DOI: 10.1111/j.13652699.2010.02300.x.

BACC. 2008. Assessment of Climate Change for the Baltic Sea Basin. Springer-Verlag: Berlin.

Barry RG, Chorley RJ. 1987. Atmosphere, Weather, and Climate, 5th edn, Methuen \& Co.: New York, 460pp.

Benestad RE. 2002. Empirically downscaled multimodel ensemble temperature and precipitation scenarios for Norway. Journal of Climate 15: 3008-3027.

Benestad RE. 2004. Tentative probabilistic temperature scenarios for northern Europe. Tellus 56: (A): 89-101. 
Betts, A. 2011. Seasonal climate transitions in New England. Weather 66: $245-248$.

Blandford T, Humes K, Harshburger B, Moore B, Walden V, Ye H. 2008. Seasonal and synoptic variations in near-surface air temperature lapse rates in a mountainous basin. Journal of Applied Meteorology and Climatology 47(1): 249-261, DOI: 10.1175/2007JAMC1565.1.

Blennow K, Persson P. 1998. Modelling local-scale frost variations using mobile temperature measurements with a GIS. Agricultural and Forest Meteorology 89: 59-71.

Bolstad PV, Swift L, Collins F, Régnière J. 1998. Measured and predicted air temperature at basin to regional scales in the southern Appalachian mountains. Agricultural and Forest Meteorology 91 $161-176$.

Bond G, Showers W, Cheseby M, Lotti R, Almasi P, deMenocal P, Priore P, Cullen H, Hajdas I, Bonani G. 1997. A pervasive millennial-scale cycle in North Atlantic Holocene and glacial climates. Science 278: 1257-1266.

Bond G, Kromer B, Beer J, Muschler R, Evans MN, Showers W, Hoffman S, Lotti-Bond R, Hajdas I, Bonani G. 2001. Persistent solar influence on North Atlantic climate during the Holocene. Science 294: 2130-2136.

Brooks SJ. 2006. Fossil midges (Diptera: Chironomidae) as palaeoclimate indicators for Eurasian region. Quaternary Science Reviews 25: 1894-1910.

Clements CB, Whiteman CD, Horel JD. 2003. Cold air pool structure and evolution in a mountain basin: Peter Sinks, Utah. Journal of Applied Meteorology 42: 752-768, DOI: 10.1175/1520-0450 (2003) $042<0752$ : CSAEIA $>2.0$. CO;2.

Cullen RM, Marshall SJ. 2011. Mesoscale temperature patterns in the rocky mountains and foothills region of Southern Alberta. Atmosphere-Ocean: 1-17.

Daly C, Conklin DR, Unsworth MH. 2009. Local atmospheric decoupling in complex topography alters climate change impacts. International Journal of Climatology 30: 1857-1864.

Dobrowski SZ, Abatzoglou J, Greenberg JA, Schladow G. 2009. How much influence does landscape-scale physiography have on air temperature in a mountain environment? Agricultural and Forest Meteorology 149: 1751-1758.

Dobrowski SZ. 2011. A climatic basis for microrefugia: the influence of terrain on climate. Global Change Biology 17(2): 1022-1035, DOI: $10.1111 / \mathrm{j} .1365-2486.2010 .02263 . x$.

Gustavsson T, Karlsson M, Bogren J, Lindqvist S. 1998. Development of temperature patterns during clear nights. Journal of Applied Meteorology 37: 559-571, DOI: 10.1175/1520-0450 (1998)037<0559:DOTPDC>2.0.CO;2.

Gutman G, Reissell A. 2010. (eds). Eurasian Arctic Land Cover and Land Use in a Changing Climate. Springer-Verlag: London/New York.

Hyvärinen V. 2003. Trends and characteristics of hydrological time series in Finland. Nordic Hydrology 34: 71-90.

Iijima Y, Shinoda M. 2000. Seasonal changes in the cold-air pool formation in a subalpine hollow, central Japan. International Journal of Climatology 20: 1471-1483, DOI: 10.1002/1097-0088 (200010)20: 12<1471:: AIDJOC554>3.0.CO; 2-6.

Isaken ISA, Gauss M, Myhre G, Walter Anthony KM, Ruppel C. 2011. Strong atmospheric chemistry feedback to climate warming from Arctic methane emissions. Global Biogeochemical Cycles 25 GB2002, DOI: 10.1029/2010 GB003845.

IPCC. 2007. Climate Change 2007. Contribution of Working Group II to the Fourth Assessment Report of the Intergovernmental Panel on Climate Change, Parry ML, Canziani OF, Palutikof JP, van der Linden PJ, Hanson CE (eds). Cambridge University Press: Cambridge, United Kingdom and New York, NY, USA.

Jepsen JU, Hage SB, Ims RA, Yoccoz NG. 2008. Climate change and outbreaks of the geometrids Operophtera brumata and Epirrita autumnata in subarctic birch forest: evidence of a recent outbreak range expansion. Journal of Animal Ecology 77: 257-264.

Jones PD, Hulme M, Briffa KR. 1993. A comparison of Lamb circulation types with an objective classification scheme. International Journal of Climatology 13: 655-663, DOI: 10.1002/joc.3370130606.

Jylhä K, Tuomenvirta H, Ruosteenoja K. 2004. Climate change projections for Finland during the 21 st century. Boreal Environment Research 9: 127-152.
Kistler R, Kalnay E, Collins W, Saha S, White G, Woollen J, Chelliah M, Ebisuzaki W, Kanamitsu M, Kousky V, van den Dool H, Jenne R, Fiorino M. 2001. The NCEP-NCAR 50-year reanalysis: Monthly means CD-Rom and documentation. Bulletin of the American Meteorological Society 82(2): 247-268.

Lamb HH. 1972. British Isles weather types and a register of daily sequence of circulation patterns, 1861-1971. Geophysics Memory 116: 85 pp., Her Majesty's Stn. Off., London.

Lemke P, Ren J, Alley RB, Allison I, Carrasco J, Flato G, Fujii Y, Kaser G, Mote P, Thomas RH, Zhang T. 2007. Observations: changes in snow, ice and frozen ground. Chapter 4. In Climate Change 2007: The Physical Science Basis. Contribution of Working Group I to the Fourth Assessment Report of the Intergovernmental Panel on Climate Change, Solomon S, Qin D, Manning M, Chen Z Marquis M, Averyt KB, Tignor M, Miller HL (eds). Cambridge University Press: Cambridge, United Kingdom and New York, NY, USA

Lookingbill TR, Urban DL. 2003. Spatial estimation of air temperature differences for landscape-scale studies in montane environments. Agricultural and Forest Meteorology 114: 141-151.

Losleben ML, Pepin NC, Pedrick S. 2000. Relationships of precipitation chemistry, atmospheric circulation and elevation at two sites on the Colorado Front Range. Atmospheric Environment 34: 1723-1737, DOI: 10.1016/S1352-2310(99) 00431-8.

Lundquist J, Cayan D. 2007. Surface temperature patterns in complex terrain: daily variations and long-term change in the central Sierra Nevada, California. Journal of Geophysics Research 112: D11124, DOI: $10.1029 / 2006 J D 007561$.

Lundquist JD, Pepin N, Rochford C. 2008. Automated algorithm for mapping regions of cold-air pooling in complex terrain. Journal of Geophysics Research 113: D22107, DOI: 1029/2008JD009879.

Luoto TP. 2009. Subfossil Chironomidae (Insecta: Diptera) along a latitudinal gradient in Finland: development of a new temperature inference model. Journal of Quaternary Science 24(2): 150-158.

Marshall SJ, Sharp MJ, Burgess DO, Anslow FS. 2007. Near-surfacetemperature lapse rates on the Prince of Wales Icefield, Ellesmere Island, Canada: implications for regional downscaling of temperature. International Journal of Climatology 27(3): 385-398, DOI: $10.1002 /$ joc. 1396.

Minder JR, Mote PW, Lundquist JD. 2010. Surface temperature lapse rates over complex terrain: lessons from the Cascade Mountains. Journal of Geophysics Research 115: D14122, DOI: 10.1029/2009JD013493.

Moberg A Tuomenvirta H, Nordli Ø. 2005. Recent climatic trends. In The Oxford Regional Environment Series: Physical Geography of Fennoscandia, Seppälä M (ed). Oxford University Press: New York, $113-133$.

Neff WD, King CW. 1989. The accumulation and pooling of drainage flows in a large basin. Journal of Applied Meteorology 28: 518-529, DOI: $10.1175 / 1520-0450$ (1989)028<0518:TAAPOD $>2.0$. CO;2.

Orlandini S, Marta AS, Mancini M. 2006. The agroclimatic analysis at farm scale. Meteorological Applications (Supplement) 87-93, DOI: $10.1017 / \mathrm{S} 1350482706002593$.

Pepin N, Benham D, Taylor K. 1999. Modeling lapse rates in the maritime uplands of northern England: implications for climate change. Arctic, Antarctic and Alpine Research 31(2): 151-164.

Pepin NC, Seidel DJ. 2005. A global comparison of surface and freeair temperatures at high elevations. Journal of Geophysics Research 110: D03104, DOI: 10.1029/2004JD005047.

Pepin NC, Schaefer MK, Riddy LD. 2009. Quantification of the coldair pool in Kevo Valley, Finnish Lapland. Weather 64: 60-67.

Pepin NC, Daly C, Lundquist J. 2011. The influence of surface versus free - air decoupling on temperature trend patterns in the western United States. Journal of Geophysics Research 116: D10109, DOI: 10.1029/2010JD014769.

Rolland C. 2003. Spatial and seasonal variations of air temperature lapse rates in Alpine regions. Journal of Climate 16(7): 1032-1046.

Serreze MC, Francis JA. 2006. The Arctic amplification debate. Climatic Change 76: 241-264.

Trivedi MR, Morecroft MD, Berry PM, Dawson TP. 2008. Potential effects of climate change on plant communities in three montane nature reserves in Scotland, UK. Biological Conservation 141: $1665-1675$ 
Vainio E. 2011. The Kevo Research Station. Retrieved from http://kevo.utu.fi/en/.

Vajda A, Venäläinen A. 2003. The influence of natural conditions on the spatial variation of climate in Lapland, northern Finland. International Journal of Climatology 23: 1011-1022.

Virtanen T, Neuvonen S, Nikula A. 1998. Modelling topoclimatic patterns of egg mortality of Epirrita autumnata (Lepidoptera: Geometridae) with a geographical information system: predictions for current climate and warmer climate scenarios. Journal of Applied Ecology 35: 311-322, DOI: 10.1046/j.1365-2664.1998.00299.x.

Weckström J, Korhola A. 2001. Patterns in the distribution, composition and diversity of diatom assemblages in relation to ecoclimatic factors in Arctic Lapland. Journal of Biogeography 28: $31-45$.

Whiteman CD. 1982. Breakup of temperature inversions in deep mountain valleys: part I. Observations. Journal of Applied Mete- orology 21: 270-289, DOI: 10.1175/1520-0450 (1982)021<0270: BOTIID $>2.0 . \mathrm{CO} ; 2$.

Whiteman CD, Bian X, Zhong S. 1999. Wintertime evolution of the temperature inversion in the Colorado Plateau basin. Journal of Applied Meteorology 38: 1103-1117, DOI: 10.1175/1520-0450 (1999) $038<1103$ :WEOTTI $>2.0$. CO;2

Whiteman CD, Pospichal B, Eisenbach S, Weihs P, Clements CB, Steinacker R, Mursch-Radlgruber E, Dorninger M. 2004. Inversion breakup in small Rocky Mountain and Alpine basins. Journal of Applied Meteorology 43: 1069-1082, DOI: 10.1175/1520-0450 (2004)043<1069:IBISRM>2.0.CO;2.

Zhenlin Y, Hanna E, Callaghan TV. 2011. Modelling surface-airtemperature variation over complex terrain around Abisko, Swedish Lapland: uncertainties of measurements and models at different scales. Geografiska Annaler: Series A, Physical Geography, DOI: 10.1111/j.1468-0459. 2011.00005.x. 